$\xi=$

\title{
Natural Dyes from Chlorella Vulgaris sp Extracted via Supercritical Fluid Extraction Dyed on Silk Fabric
}

\author{
A.F. Che Rahim ${ }^{1}$, M.R. Ahmad ${ }^{2}$, K. Ismail ${ }^{3}$, M.I. Ab Kadir ${ }^{4}$ \\ Textile Research Group, Faculty of Applied Sciences, Universiti Teknologi MARA, 40450 Shah Alam, Selangor, Malaysia. \\ *Corresponding author E-mail: rozitex@salam.uitm.edu.my
}

\begin{abstract}
Of late, research on natural dyes is increasing due to its eco-friendly and less hazardous nature towards humankind. This study focuses on the colour coordinates and colour strength of dyes from Chlorella Vulgaris sp extracted via Supercritical Fluid Extraction (SFE). The SFE optimum parameters for yield extracts were obtained through response surface methodology along with central composite design approach. Exhaustion dyeing with meta-chrome method was performed on silk fabrics for 60 minutes at $85^{\circ} \mathrm{C}$. The dyed silk fabrics were measured and analysed for their colourimetric and fastness properties in accordance to MS ISO and AATCC standards, respectively. The colour shades on the dyed silk fabrics using alum mordant were light brown while for the iron mordant were dark brown. These shades were confirmed with the colour coordinates, $\mathrm{L}^{*} \mathrm{a}^{*} \mathrm{~b}^{*}$, values of the fabrics. The colour strengths of the fabrics dyed with the iron mordant at $2 \%$ and $5 \%$ dyes were the highest in comparisons with other dyed fabrics. Overall, the colourfastness of the fabrics to washing were quite low but with very good colour staining ratings and fastness to perspiration, rubbing and light.
\end{abstract}

Keywords: Chlorella Vulgaris sp; Colour Strength; Fastness Properties; Natural Dyes; Supercritical Fluid Extraction (SFE)

\section{Introduction}

Textile researchers and industrialists are subjected to challenges in discovering new development for the textile industry due to global concerns in environmental control. Current industries and social demands have raised awareness on the use of natural dyes as a source of textile coloration due to the hazardous implications from the processing and the usage of synthetic dyes [1]. More research needs to be conducted to select potential natural dyes source and to study the optimum yield of dye extracted from the natural sources to be reasonably applied on textile coloration. Natural dyes are considered to be ecologically clean product, and these make them the best choice to replace synthetic dyes. The need for qualitative and non-perishable natural dyes is increasing [2][3]. Nowadays there are many researches on the natural dyes from the plants and microorganisms that have been carried out [3][4][5]. The natural dyes particularly derived from its resources which are from natural plants, animals, minerals and microbial [4]. However, the use of natural dyes in the textile industry is not as high as the synthetic dyes due to limitations and inconsistency in shades and poor colourfastness [6].

If natural dyes are used alone, many limitations can be found in terms of fastness and brilliancy of shade. But, when the dyes are used along with mordant they produce bright and fast colours. Consequently, instead of using unsustainable technology for producing colours, mild chemistry can be used to attain almost parallel results. The rich biodiversity has provided us abundant of raw materials hence; sustainable linkage must be developed between cultivation, collection and their use [7]. There are two processes concerned when dyeing with natural dye; the first is mordanting and the second is applying the dye. The mordanting prepares the fabric to receive the dyes and allow dye molecules to bind to the fibre [8]. However, not all plant dyes need mordants to achieve good colour. Some plant dyes already contain qualities that will bind the colour to the fibre without any additives. There are several natural dyes derived from flora and fauna that contain dye compounds and will adhere directly to the fibre without mordanting. The use of mordants, though not a necessity, is still sometimes an advantage particularly to obtain a variety of shades, to increase the dye uptake and to improve the colourfastness.

The microalgae is one of the main source of the carotenoids that can be obtained in a large yield of production[9]. The cell wall of the microalgae is where the role in adsorption process stored carotenoids pigmentation and create electrostatic attraction[10]. In some previous studies, microalgae of chlorella vulgaris $s p$. are used to treat wastewater due to its capability of absorbing toxicity and harmful chemicals in textile wastewater thus reduce the concentration of contaminants [10][11]. The main concern on selecting this type of microalgae species is that it is widely used in textile treatments since it can absorb the toxicity of the wastewater. Meanwhile, the chlorella vulgaris $s p$ also used in pharmaceutical industry as one of the great antioxidants to the human beings [12]. A previous study investigated that chlorella vulgaris $s p$ is rich in nutrients such as carbohydrates, vitamins, proteins and minerals that used as the substitution of food for the daily life. In comparison, this study is concerning on carotenoids pigmentation to obtain the optimum yield of colourants via supercritical carbon dioxide $\left(\mathrm{SC}-\mathrm{CO}_{2}\right)$ with the parameters (e.g., pressure, temperature and dynamic extraction time).

According to Mendes et. al. [9], the colourants extracted from supercritical carbon dioxide are free from any toxicity and harmful of some chemical solvents. Most recently, many natural resources are separated from its properties by supercritical carbon dioxide $\left(\mathrm{SC}-\mathrm{CO}_{2}\right)$ since the efficiency of extraction process that can obtain different valuable compounds [13]. The application of $\mathrm{SC}_{-} \mathrm{CO}_{2}$ is 
not just limited to certain field such as textile industry but also involves in food industry and pharmacy [14]. In addition, SC-CO2 is a method based on the utilization of $\mathrm{CO} 2$ under its supercritical conditions which is suitable for extraction of a variety of compounds as well as preferably used in dyeing of textile due to its high efficiency technology [15][16]. SC-CO2 is a fluid state whenever the temperature and pressure of Carbon dioxide $(\mathrm{CO} 2)$ is at above it critical points. Moreover, $\mathrm{SC}-\mathrm{CO}_{2}$ uses carbon dioxide $\left(\mathrm{CO}_{2}\right)$ as its solvents in which the $\mathrm{CO}_{2}$ gaseous are environmentally friendly, can be recycled, non-toxicity and chemically inert [13][17]. Furthermore, SC-CO2 is classified as a supercritical fluid (SFE), which has high diffusivity and low viscosity and can diffuse easily through solid materials. This condition will eventually allow higher extraction yields. In this extraction process of SC- $\mathrm{CO}_{2}$, there are important parameters that need to be aware like pressure, temperature and time. The optimization of the experimental design of SC-CO2 can be derived from response surface methodology (RSM). As explained by Yavari, RSM is a tool that evaluate the correlation between effective variables and responses in which aim to optimize the conditions process[18]. Therefore, it will reduce the cost of trials and time effective for the researchers to get the optimization design for its study. Not just that, it is proven that SFE using $\mathrm{CO}_{2}$ as a solvent has provided a good alternative to the use of chemical solvents [19].

\section{Materials and Methods}

\subsection{Materials and reagents}

Chlorella vulgaris sp. (Figure 1) was used as the dye source and purchased from Tropical Bioessence Sdn. Bhd. (Malaysia). This dye was selected due to its carotenoids pigmentation that can be obtained as natural dye. High purity Carbon Dioxide $\left(\mathrm{CO}_{2}\right)$ $(99.995 \%)$ was used and purchased from Pure Dimension Sdn. Bhd. (Malaysia). Hundred percent $(100 \%)$ satin weave silk fabric was used as the textile substrate. In each different bath, two percent (2\%) of metallic salt of aluminium potassium sulphate (alum) and iron(II) sulphate (iron) were used as mordants.

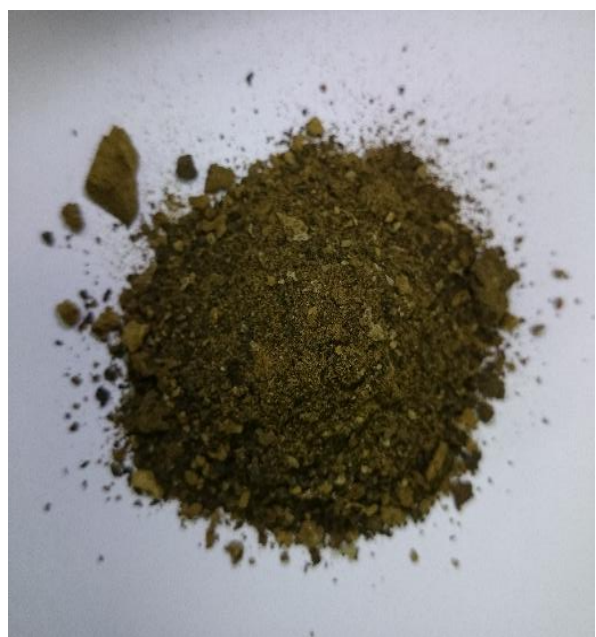

Fig. 1: Chlorella Vulgaris sp

\subsection{Dye Extraction}

The dye extraction process was carried out through Supercritical Fluid Extraction (SFE) machine OV-SCF-10000 Model from Taiwan Supercritical Technology Co. Ltd. An experimental design approach through response surface methodology (RSM) was developed for SFE using Design-Expert 6.0.4 (Stat-Ease Software). The SFE method was used to extract the Chlorella vulgaris sp. with the use of high purity $\mathrm{CO}_{2}$ for 2 hours at 100 degrees Celsius $\left({ }^{\circ} \mathrm{C}\right)$ and with the pressure of $4500 \mathrm{psi}$.

\subsection{Dyeing and Mordanting of Silk Fabric}

Exhaustion dyeing technique was carried out on the $100 \%$ satin silk fabric using the extracted Chlorella vulgaris $s p$. colourant. Two percent (2\%) and five percent (5\%) of the extracted Chlorella vulgaris $s p$. of liquid solution, based on weight of fabric (owf), were used to dye the silk fabric using a liquor ratio of 1:10. Two percent $(2 \%)$ of mordant was used to bind the dye onto the silk fabric. Meta chrome method, simultaneous dyeing and mordanting, was used. This method was performed for one hour at $85^{\circ} \mathrm{C}$. After the dyeing cycle was completed, the dyed fabrics were washed, rinsed with tap water and then left to dry.

\subsection{Colourfastness Properties}

The dyed fabrics were assessed in terms of colourfastness to washing, perspiration, rubbing/crocking and light. The visual evaluation was evaluated according to MS ISO Standard as listed in Table 1 and AATCC Gray Standard. The samples were compared with the Gray Scale and ratings given. The AATCC standard scale and numerical ratings were applied in the testing. The scale for change in colour and staining is from 1 to 5 where the lowest rating is 1 and the highest rating is 5 .

Table 1: Standard Methods Used for the Colourfastness Assessment

\begin{tabular}{|c|c|c|}
\hline Colourfastness & Standard Methods & Equipments \\
\hline \multirow{3}{*}{ Washing } & MS ISO 105-C01-1966 & Auto-wash \\
\cline { 2 - 3 } & MS ISO 105-A05-2003 & Change in Colour \\
\cline { 2 - 3 } & MS ISO 105-A04-2003 & Staining \\
\hline \multirow{3}{*}{$\begin{array}{c}\text { Perspiration } \\
\end{array}$} & MS ISO 105-E04-1996 & Perspirometer \\
\cline { 2 - 3 } & MS ISO 105-A05-2003 & Change in Colour \\
\cline { 2 - 3 } & MS ISO 105-A04-2003 & Staining \\
\hline \multirow{2}{*}{$\begin{array}{l}\text { Rubbing/ } \\
\text { Crocking }\end{array}$} & MS ISO 105-X12-2001 & Crockmeter \\
\cline { 2 - 3 } & MS ISO 105-A04-2003 & Staining \\
\hline Light & MS ISO 105-B02-2001 & Light Fastness Tester \\
\hline
\end{tabular}

\subsection{Color Assessments}

The K/S value (colour strength) of extracted dyes was measured by using HunterLab LabScan XE (LSXE) spectrophotometer. The samples were analysed using HunterLab EasyMatchQC software under illuminant D65/100 standard observer. The percentage of reflectance curves for each dyed fabric was measured by capturing their shades. The colour coordinate values (CIE L*a*b*) were visualized and the reflectance of the dyed fabrics was measured. The $\mathrm{L}^{*}$ values indicate perceived lightness or darkness. Value of 0 indicates black and 100 indicates white. The values of $a^{*}$ indicate red $(+a)$ and green $(-a)$ while $b^{*}$ indicates yellow $(+b)$ and blue $(-$ b).

The colour strength $(\mathrm{K} / \mathrm{S})$ values were calculated in accordance to the Kubelka-Munk equation (1) to determine the dye uptake of each dyed fabrics at maximum absorption wavelength from the reflectance value.

$K / S=\frac{[1-0.01 R]}{2[0.01 R]}$

Where $\mathrm{K}$ is the dye absorption; $\mathrm{S}$ is the light scattering characteristics of the natural dyes which depend on the nature of the substrate used; $\mathrm{R}$ is the spectral reflectance value of the coloured textile material at peak wavelength.

\section{Results and Discussion}

\subsection{Colour Shades of the dyed samples}

Figure 2 shows the shades obtained from the chlorella vulgaris $s p$. extracted using SFE on the silk fabrics with different mordants 
and percent of dye. A variety of colour shades were obtained with respect to the nature of the mordants. The silk dyed fabrics using alum as the mordant showed light brown in colour. While for the iron mordant, the silk fabrics were much darker. In terms of the dye percent, there were just some slight difference between the colour shades for both fabrics.

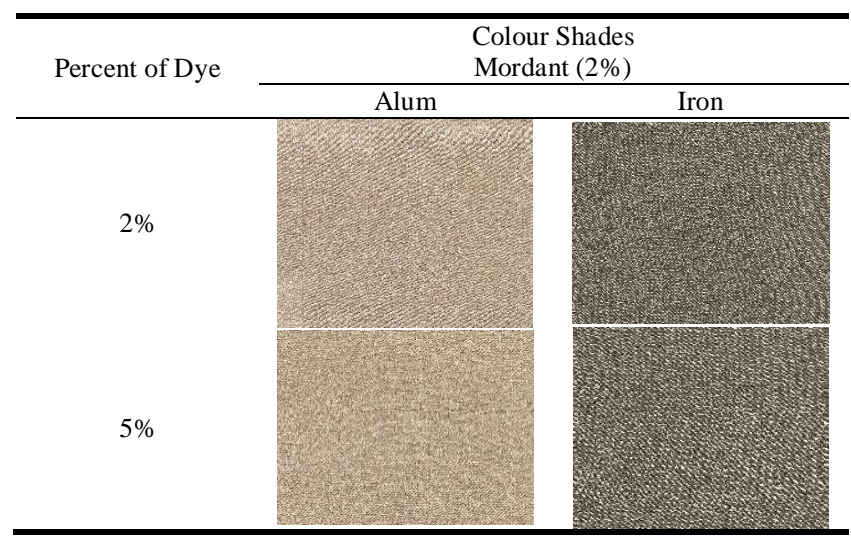

Fig. 2: Colour Shades of Dyed Fabric

\subsection{Colour Coordinates of the dyed samples}

The values of colour coordinates $\left(\mathrm{L}^{*} \mathrm{a}^{*} \mathrm{~b}^{*}\right)$, colour strength $(\mathrm{K} / \mathrm{S})$ for the dyed fabrics obtained from the measurements using LabScan XE processed in this study are shown in Table 2.

The L* (colour lightness) values of the control sampled (untreated silk) was 90.60 . In the mordanting method, the $\mathrm{L}^{*}$ values indicating the deepening of the shades. The use of mordants also increased $\mathrm{a}^{*}$ and $\mathrm{b}^{*}$ values which can be considered as the colour becoming more saturated and browner.

Table 2: $\mathrm{L}^{*} \mathrm{a}^{*} \mathrm{~b}^{*}$ and K/S Values of Chlorella Vulgaris $s p$

\begin{tabular}{|c|c|c|c|c|}
\hline Sample & $\mathrm{L}^{*}$ & $\mathrm{a}^{*}$ & $\mathrm{~b}^{*}$ & $\mathrm{~K} / \mathrm{S}$ \\
\hline Untreated Silk & 90.60 & -0.03 & 4.55 & 0.12 \\
\hline 2\% Alum 2\% Dye & 79.21 & 3.60 & 14.02 & 0.69 \\
\hline 2\% Iron 2\% Dye & 58.61 & 0.72 & 8.41 & 2.20 \\
\hline 2\% Alum 5\% Dye & 77.90 & 3.61 & 14.20 & 0.74 \\
\hline 2\% Iron 5\% Dye & 58.88 & 0.94 & 9.36 & 2.30 \\
\hline
\end{tabular}

The values of $\mathrm{a}^{*}$ and $\mathrm{b}^{*}$ were plotted into $2 \mathrm{D}$ colour coordinates, as shown in Figure 3, to show their shade regions. All the dyed silk fabrics mordanted by alum and iron showed yellowish shade in their hue. Both coordinates were confirmed by their lower positive $\mathrm{a}^{*}$ but highly positive $\mathrm{b}^{*}$.

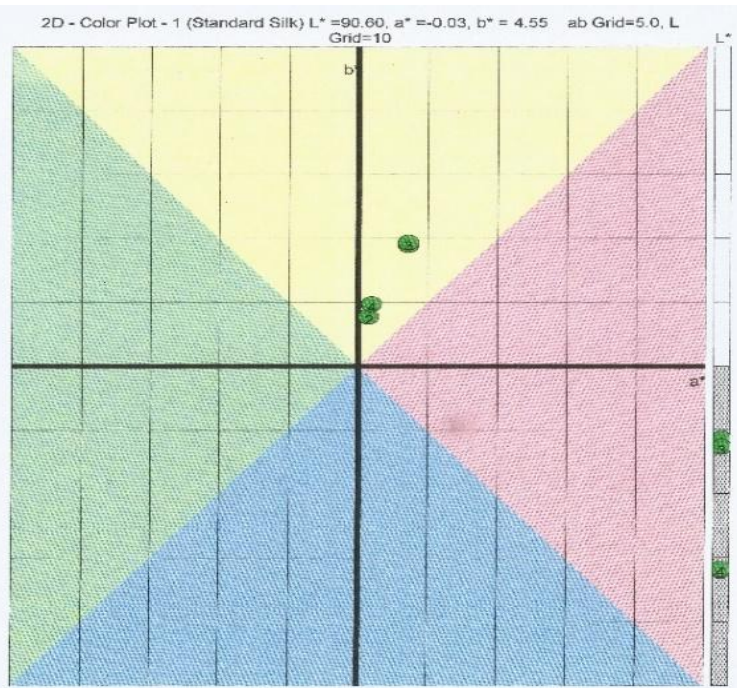

Fig. 3: 2D Colour Plot of Fabric Dyed with Chlorella Vulgaris sp.

\subsection{Colour Strength $(\mathrm{K} / \mathrm{S})$ of the dyed samples}

The different mordants not only resulted in the difference in shades of colour and changes in $\mathrm{L}^{*}$ values but also changes to their K/S values as well. The K/S values of the dyed silk fabrics from chlorella vulgaris sp. can be seen in Figure 4. The K/S values for all samples may seem low since the dye concentration in plants are rather low compared to those of synthetic dyes, but the values are still acceptable. It appears that adding mordants to the dyeing bath influenced the colour strength of the dyed silk fabrics. The metallic mordants helps the dye molecules to bond with the fibres.

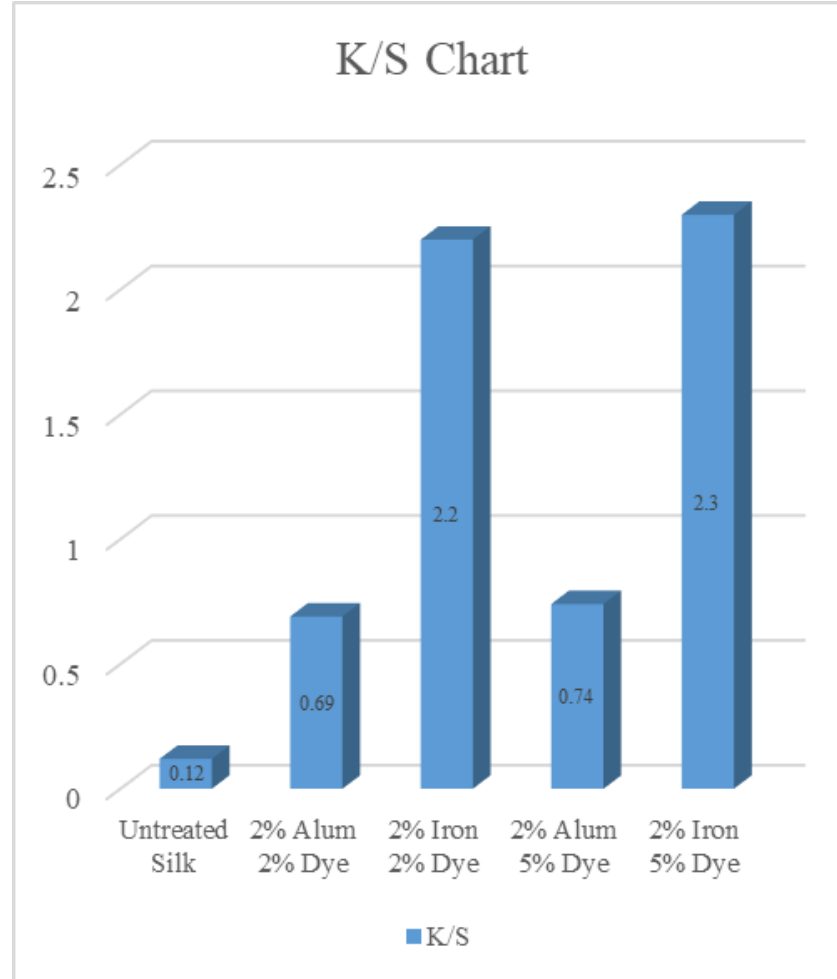

Fig. 4: Colour Strength $(K / S)$ Values of Chlorella Vulgaris sp Dyed on Silk Fabric

\subsection{Colourfastness Properties of dyed samples}

The dyeing fastness properties of the dyed silk fabrics are listed in Table 3-6. As for washing fastness, the colour change ratings were bad for all of the dyed fabrics since the colour appreciable loss (2,3 and 3/4). However, the colour staining ratings were very good to excellent $(4,4 / 5$ and 5$)$ on cotton and silk fabric.

The fastness to perspiration showed very good to excellent rating (4/5 and 5) for both colour change and staining of adjacent fabric of cotton and silk on alum dyed silk fabrics. While the mordant silk dyed fabric with iron showed poor rating $(2$ and $2 / 3)$ for their colour change. But the staining on cotton and silk fabric for the iron mordanted dyed fabric of $2 \%$ dye showed very good to excellent rating ( $4 / 5$ to 5 ) but different with $5 \%$ dye showed good rating (3/4 and 4).

Table 3: Fastness Properties to Washing

\begin{tabular}{|c|c|c|c|}
\hline \multirow{2}{*}{ Sample } & \multicolumn{3}{|c|}{ Washing } \\
\cline { 2 - 4 } & \multirow{2}{*}{$\begin{array}{c}\text { Colour } \\
\text { Change }\end{array}$} & \multicolumn{2}{|c|}{ Staining } \\
\cline { 3 - 4 } & & Cotton & Silk \\
\hline $2 \%$ Alum 2\% Dye & $3 / 4$ & 5 & $4 / 5$ \\
\hline $2 \%$ Iron 2\% Dye & 2 & 4 & 4 \\
\hline $2 \%$ Alum 5\% Dye & 3 & 4 & 4 \\
\hline $2 \%$ Iron 5\% Dye & 2 & & $4 / 5$ \\
\hline
\end{tabular}


Table 4: Fastness Properties to Perspiration

\begin{tabular}{|c|c|c|c|}
\hline \multirow{2}{*}{ Sample } & \multicolumn{3}{|c|}{ Perspiration } \\
\cline { 2 - 4 } & \multirow{2}{*}{ Colour Change } & \multicolumn{2}{c|}{ Staining } \\
\cline { 2 - 4 } & & Cotton & Silk \\
\cline { 2 - 4 } & $4 / 5$ & 5 & 5 \\
\hline $2 \%$ Alum 2\% Dye & 2 & $5 / 5$ & $5 / 5$ \\
\hline $2 \%$ Iron 2\% Dye & 4 & 4 & $3 / 4$ \\
\hline $2 \%$ Alum 5\% Dye & $2 / 3$ & & \\
\hline
\end{tabular}

Table 5: Fastness Properties to Rubbing/Crocking

\begin{tabular}{|c|c|c|c|c|}
\hline \multirow{2}{*}{ Sample } & \multicolumn{4}{|c|}{ Rubbing/Crocking } \\
\cline { 2 - 5 } & \multicolumn{4}{|c|}{ Staining } \\
\cline { 2 - 5 } & Dry & Wet & Dry & Wet \\
\hline $\begin{array}{c}2 \% \text { Alum } \\
\text { 2\% Dye }\end{array}$ & $4 / 5$ & 5 & $4 / 5$ & $4 / 5$ \\
\hline $\begin{array}{l}2 \% \text { Iron } \\
\text { 2\% Dye }\end{array}$ & $3 / 4$ & $3 / 4$ & $3 / 4$ & $3 / 4$ \\
\hline $\begin{array}{c}\text { 2\% Alum } \\
\text { 5\% Dye }\end{array}$ & 4 & $4 / 5$ & 4 & 4 \\
\hline $\begin{array}{l}2 \% \text { Iron } \\
\text { 5\% Dye }\end{array}$ & $3 / 4$ & $3 / 4$ & 3 & 4 \\
\hline
\end{tabular}

Table 6: Fastness Properties to Light

\begin{tabular}{|c|c|c|}
\hline \multirow{2}{*}{ Sample } & \multicolumn{2}{|c|}{ Light } \\
\cline { 2 - 3 } & Colour Change & Blue Wool \\
\hline $2 \%$ Alum 2\% Dye & $4 / 5$ & 7 \\
\hline $2 \%$ Iron 2\% Dye & 4 & 7 \\
\hline $2 \%$ Alum 5\% Dye & $4 / 5$ & 6 \\
\hline $2 \%$ Iron 5\% Dye & 4 & \\
\hline
\end{tabular}

The dyed silk fabrics mordanted by alum $2 \%$ and $5 \%$ showed very good to excellent rating (4/5 and 5) on the dry and wet staining cloth. However, the iron mordanted fabrics showed fair to good rating $(3,3 / 4$, and 4$)$. Last but not least, the light fastness for all dyed silk fabrics showed good to very good rating (4 and 4/5) and for the blue wool rating, it showed excellent rating of dyed silk fabric with alum since there is slightly fading while good to very good rating (5 and 6) on dyed silk fabric with iron since it is moderately fading.

\subsection{Colour Reflectance of the dyed samples}

Reflectance is defined as the amount of light reflected by an object at different wavelengths. The higher reflectance percentage indicates lighter shades of the dyed colour while lower reflectance percentages represent darker colour shade. As shown in Figure 5, the reflectance curves of the silk fabrics dyed with chlorella vulgaris sp. using exhaustion dyeing with different mordant attained similar shapes to the respective dye percent of $2 \%$ and $5 \%$, where the reflectance (\%R) was increased from $400 \mathrm{~nm}$ to $700 \mathrm{~nm}$ steadily. It was observed that the reflectance spectra of the mordanted fabrics was considerably less than that of the control sample indicating that the colour strengths of the mordanted fabrics were higher than the control sample. Mordants play a very important role in imparting and fixing the colour onto the fabric.

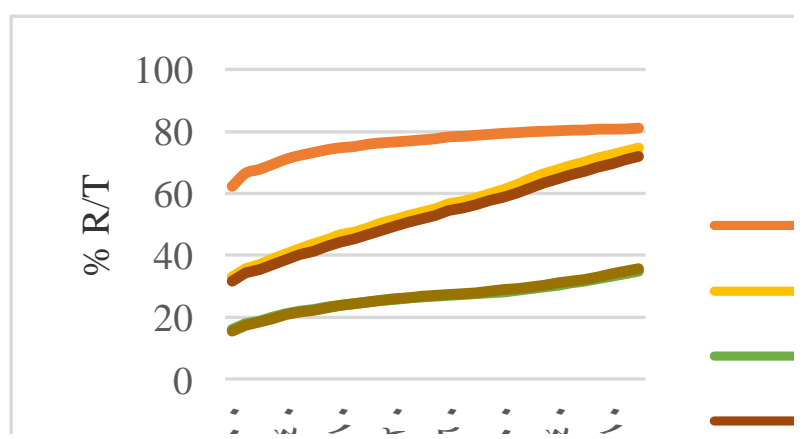

Fig. 5: Reflectance Curves of Silk Fabric Dyed with Chlorella Vulgaris sp

\section{Conclusion}

This study investigated the dyeing performances and fastness of natural dyes extracted from Chlorella vulgaris $s p$. It can be concluded that Chlorella vulgaris sp. can be utilized as a natural dye source which produces beautiful and unique shades on silk fabrics. This study also suggests $\mathrm{SC}-\mathrm{CO}_{2}$ extraction is a good method of extraction since it is an environmentally friendly technology with great yield extract. The fastness properties of the dyed silk fabrics gave good to excellent rating on dyed silk fabric mordanted with alum compared to mordanted with iron except for colour change of washing properties considered as poor. In terms of the percent dye, there is some slight difference since the rating of fastness, $\% \mathrm{R}$ and $\mathrm{K} / \mathrm{S}$ values showed almost the same findings.

\section{Acknowledgement}

The authors acknowledge the financial support obtained from the Research Management Center (RMC) of Universiti Teknologi MARA under the Research Initiative Grant (600-IRMI/MYRA 5/3/GIP (039/2017). Thanks, are also due to the Faculty of Applied Sciences, UiTM Shah Alam for the facilities and resources given in completing the project.

\section{References}

[1] A. K. Samanta and P. Agarwal, "Application of natural dyes on textiles," Indian J. Fibre Text. Res., vol. 34, no. December, pp. 384-399, 2009.

[2] W. Y. W. Ahmad, R. Rahim, M. R. Ahmad, M. I. A. Kadir, and M. I. Misnon, "The application of Gluta aptera wood ( Rengas ) as natural dye on silk and cotton fabrics," Univers. J. Environ. Res. Technol., vol. 1, no. 4, pp. 545-551, 2011.

[3] J. Lee, M. H. Kang, K. B. Lee, and Y. Lee, "Characterization of natural dyes and traditional korean silk fabric by surface analytical techniques," Materials (Basel)., vol. 6, no. 5, pp. 2007-2025, 2013.

[4] S. Saxena and A. S. M. Raja, "Natural Dyes: Sources, Chemistry, Application and Sustainability Issues," in Roadmap to Sustainable Textiles and Clothing, Singapore: Springer, 2015, pp. 37-80.

[5] M. Shahid, Shahid-Ul-Islam, and F. Mohammad, "Recent advancements in natural dye applications: A review," J. Clean. Prod., vol. 53, pp. 310-331, 2013.

[6] B. M. Ángeles, B. O. U. Eva, M. Ignacio, and D. Pablo, "Dyeing Cotton With Eisenia Bicyclis As Natural Dye Using Different Biomordants," pp. 9-12, 2015.

[7] V. Vignesh, S. Chakrabarti, and S. C. Srivastava, "An experimental study on the load modelling using PMU measurements," in 2014 IEEE PES T\&D Conference and Exposition, 2014, no. April, pp. 15 .

[8] S. B. Ummalyma, E. Gnansounou, R. K. Sukumaran, R. Sindhu, A. Pandey, and D. Sahoo, "Bioflocculation: An alternative strategy for harvesting of microalgae - An overview," Bioresour. Technol., vol. 242, pp. 227-235, 2017.

[9] R. L. Mendes et al., "Supercritical $\mathrm{CO}_{2}$ extraction of carotenoids and other lipids from Chlorella vulgaris," Food Chem., vol. 53, pp. 99-103, 1995.

[10] V. V Pathak, R. Kothari, A. K. Chopra, and D. P. Singh, "Experimental and kinetic studies for phycoremediation and dye removal by Chlorella pyrenoidosa from textile wastewater," $J$. Environ. Manage., vol. 163, pp. 270-277, 2015.

[11] M. Sang, G. Du, J. Hao, L. Wang, E. Liu, and Y. Zhang, "Journal of Pharmaceutical and Biomedical Analysis Modeling and optimizing inhibitory activities of Nelumbinis folium extract on xanthine oxidase using response surface methodology," J. Pharm. Biomed. Anal., vol. 139, pp. 37-43, 2017.

[12] M. a Chia, A. T. Lombardi, and M. D. G. G. Melão, "Growth and biochemical composition of Chlorella vulgaris in different growth media.," An. Acad. Bras. Cienc., vol. 85, no. 4, pp. 1427-38, 2013.

[13] M. Bimakr, R. A. Rahman, F. S. Taip, N. M. Adzahan, M. Z. Islam Sarker, and A. Ganjloo, "Supercritical carbon dioxide extraction of seed oil from winter melon (Benincasa hispida) and its antioxidant activity and fatty acid composition," Molecules, vol. 18, no. 1, pp. 997-1014, 2013 
[14] M. Bimakr et al., "Supercritical Carbon Dioxide ( SC-CO 2 ) Extraction of Catechin , Epicatechin , Rutin and Luteolin from Spearmint ( Mentha spicata L .) Leaves," World Appl. Sci. J., vol. 5, no. 4, pp. 410-417, 2008.

[15] M. Van der Kraan, O. Bayrak, M. V. F. Cid, G. F. Woerlee, W. J. T. Veugelers, and G. J. Witkamp, "Textile dyeing in supercritical carbon dioxide," ... Supercrit. Fluids, 2003.

[16] G. A. Montero, C. B. Smith, W. A. Hendrix, and D. L. Butcher, "Supercritical fluid technology in textile processing: An overview," Ind. Eng. Chem. Res., vol. 39, no. 12, pp. 4806-4812, 2000.

[17] H. Yen, S. Yang, C. Chen, and J. Chang, "Bioresource Technology Supercritical fluid extraction of valuable compounds from microalgal biomass," Bioresour. Technol., vol. 184, pp. 291-296, 2015.

[18] S. Yavari, A. Malakahmad, N. B. Sapari, and S. Yavari, "Sorption properties optimization of agricultural wastes-derived biochars using response surface methodology," Process Saf. Environ. Prot., vol. 109, pp. 509-519, 2017.

[19] R. Halim, A. Hosikian, S. Lim, and M. K. Danquah, "Chlorophyll extraction from microalgae: A review on the process engineering aspects," Int. J. Chem. Eng., vol. 2010, 2010. 